\title{
ANÁLISE DE POLÍTICAS PÚBLICAS, SUBJETIVIDADE E PODER: MATRIZES E INTERSECÇÕES TEÓRICAS
}

\author{
Gustavo Camilo Baptista
}

Resumo: O presente artigo tem como objetivo apresentar algumas reflexões e críticas sobre as teorias de análise de políticas públicas, enfocando o papel da subjetividade nos processos de tomada de decisão e nas disputas de poder. São apresentados os principais modelos teóricos desse campo que são usados no Brasil e subsídios da Psicossociologia para compreensão das questões da subjetividade e do poder, bem como algumas de suas intersecções. Na conclusão, são apresentados alguns pontos a serem considerados na aproximação dessas duas áreas de conhecimento.

Palavras-chave: Políticas públicas. Administração pública. Poder. Subjetividade.

\section{Introdução}

O presente artigo tem por objetivo apresentar algumas reflexões e críticas sobre as teorias de análise de políticas públicas, enfocando o papel da subjetividade nos processos de tomada de decisão e nas disputas de poder. Diversos trabaIhos que contemplam uma ampla gama de abordagens teóricas da Psicologia têm apontado que essa ciência tem bastante a oferecer nos processos de formulação e implementação de políticas públicas. O próprio Conselho Federal de Psicologia tem organizado eventos e criado instâncias para subsidiar o ingresso da categoria 
nessas discussões, tal como o Centro de Referência em Psicologia e Políticas Públicas - CREPOP, formado em 2006 com o objetivo de estabelecer referências técnicas para atuação dos psicólogos em políticas públicas (Cruz \& Guareschi, 2009; Ferreira, 2008; Gonçalves, 2010; Scarparo \& Poli, 2009).

Poucos estudos, todavia, atentam para o fato de que as políticas públicas, por se situarem na interface entre o Estado e a sociedade, têm sido caracterizadas como um campo de conhecimento próprio, com referenciais teóricos e metodológicos de uma ciência aplicada que, apesar de usar sobejamente subsídios da Sociologia, da Ciência Política e da Economia, é distinta dessas. Os saberes desse campo são utilizados na elaboração das principais políticas públicas sociais de nosso país, tais como o Programa Bolsa Família, o Programa Nacional de Segurança Pública com Cidadania (PRONASCl) e o Programa de Implementação do Sistema Nacional de Atendimento Socioeducativo (Pró-SINASE),

Uma das possíveis causas para isso se relaciona com a recente inserção dessa pauta nos estudos da Psicologia. As avaliações de políticas públicas nos campos da Educação e da Saúde, por exemplo, se confundem com a própria história desse campo, cujas origens estão na década de 1950 (Dunn, 2008; Worthen, Sanders, \& Fitzpatrick, 2004).

Se para explorar as possibilidades das interfaces dos campos da Psicologia e das Políticas Públicas faz-se necessário adentrar nas questões relativas às definições dessas áreas do conhecimento, é importante ressaltar que, ao se circunscrever algo, são traçadas fronteiras que muitas vezes são imaginárias. Isso, se por um lado permite uma compreensão mais eficiente do que está sendo estudado, por outro traz em seu bojo a possibilidade do reducionismo (Morin, 2002). Tais considerações são justificadas não somente pela crescente importância das políticas públicas, mas também porque a desconsideração de algumas das especificidades desse objeto pode encobrir o complexo papel das instituições estatais nesse domínio.

Este artigo se divide em quatro partes. Na primeira, é apresentado o campo das políticas públicas. Na segunda, foram expostos subsídios da Psicossociologia para compreensão das questões da subjetividade e do poder no tocante à análise das políticas públicas. Na terceira, foram discutidas algumas intersecções entre esses dois campos. Na conclusão, são apresentados alguns pontos a serem considerados na aproximação dessas duas áreas de conhecimento.

\section{O campo das políticas públicas}

Cumpre assinalar inicialmente que as dificuldades referentes à abrangência e aos significados da expressão"política pública" relacionam- 
se inexoravelmente com a necessidade de estabelecer diferenciações e ressalvar complementaridades com a palavra"política".Isso porque o uso da expressão "política pública", por si só, parece pleonástico, afinal, em suas acepções originais na Grécia Clássica, a palavra"política"é associada intrinsecamente ao conceito de "público", diferenciando-se, assim, quase como um antônimo, da concepção de "privado" (Heidemann, 2009).

A palavra política, entretanto, adquiriu, nestes vinte e cinco séculos após o apogeu da democracia ateniense, um expressivo número de outras acepções. As sintéticas definições constantes no Dicionário Aurélio, por exemplo, constituem apenas um indício da complexidade e da abrangência desse termo.

Política [Fem. substantivado de político] S.f. 1. Ciência dos fenômenos referentes ao Estado; ciência política. 2. Sistema de regras respeitantes à direção dos negócios públicos. 3. Arte de bem governar os povos.4. Conjunto de objetivos que enformam determinado programa de ação governamental e condicionam a sua execução. 5. Princípio doutrinário que caracteriza a estrutura constitucional do Estado. 6. Posição ideológica a respeito dos fins do Estado. 7. Atividade exercida na disputa dos cargos do governo ou no proselitismo partidário. 8. Habilidade no trato das relações humanas, com vista à obtenção dos resultados desejados. 9. P. ext. Civilidade, cortesia. 10. Fig. Astúcia, ardil, artifício, esperteza (Cf. política, do verbo politicar). (Ferreira, 1986, p. 1358)

A palavra política é originalmente uma adjetivação da palavra polis que ao mesmo tempo se referia às cidades-estado da Grécia Clássica e seus modelos de organização administrativa e social. Os serviços públicos, assim como todo o espaço público, seriam parte do aspecto político do ser humano, que se contrapunha a sua natureza animal. Polis queria dizer cidade, assim todos os cidadãos livres eram chamados de politai, indivíduos com direitos e deveres comuns (Nay, 2007).

Segundo Bobbio, Mateucci e Pasquino (1998), a palavra política foi difundida pelo livro de Aristóteles, "Política”. Esse filósofo conceitua essa palavra como a ciência que tem por objeto a felicidade humana. Ele comparou sistemas de governo das diferentes cidades-estado gregas com outras nações, tentando mostrar as vantagens e desvantagens dos diferentes sistemas políticos. A influência dessa percepção da política e do Estado como associados a um meio de busca do bem comum e da sociedade como um sistema, no qual as partes dependem umas das outras, transpassou os séculos, influenciando os filósofos iluministas que contribuíram teoricamente com o desenho do Estado Moderno, tais como Montesquieu, Rousseau e Locke (Nay, 2007).

Um segundo conjunto de acepções relaciona o termo com uma doutrina, ciência ou área do conhecimento relacionada ao Estado, e para a qual hoje se emprega com maior frequência o nome de disciplinas ou 
de áreas específicas, tais como "Ciência Política”, "Filosofia Política," "Direito Constitucional" ou a "Teoria Geral do Estado".Nessa acepção, encontramos também raízes históricas na filosofia grega, porquanto é nesse período que surgem as primeiras obras relacionadas ao papel do Estado e do governante distintas da esfera religiosa, e que incluem tanto as obras de Aristóteles quanto as de Platão (Heidemann, 2009).

Um terceiro grupo de acepções relaciona "política" com um conjunto de ações para influenciar, conquistar e manter o poder. Essa acepção se aproxima dos postulados de Maquiavel. Esse autor traça um interessante paradoxo no sentido de considerar que o comportamento do governante deve seguir uma ética diferente daquela presente na sociedade. Assim, expressões como "entrar no submundo da política","politicagem" e "politiqueiro" denotam um conjunto de ações que têm por característica a busca pelo atendimento de interesses particulares e conjunturais, que podem corromper as instituições (Heidemann, 2009).

É interessante sobrelevar também que, em inglês, existe uma palavra específica para essa acepção, policy, que se distingue de politics, palavra esta mais próxima das acepções citadas anteriormente, e de polity, que se refere à estrutura organizacional do Estado. Ressalva-se também que o termo policy não é usado apenas para os objetivos da ação estatal, pois existe a expressão private policy, que abrange o que é conhecido como terceiro setor e também as empresas que atendem demandas de serviço público, tal como empresas de seguros. Usa-se public policy, dessa forma, para destacar a característica estatal.

Assim, é a partir dessa última acepção que se inicia a difusa fronteira que distingue "política" de "política pública". Alguns autores, como Dye (2002), consideram que esse conceito engloba tudo o que os governos decidem fazer ou deixar de fazer.Em outras palavras, a ausência de ações estatais também seria parte do campo de estudo das políticas públicas.

Outros autores, entretanto, consideram que uma política pública passa a existir quando o Estado passa para a ação propriamente dita, o que é estabelecido não com a existência de objetivos vagos, mas sim de elementos que mostrem ações concretas por parte do Estado. $O$ estudo dos processos envolvidos na tomada de decisão por parte dos gestores públicos, e em especial das "boas intenções e discursos formais", faria, por conseguinte, parte do campo da política. Dessa maneira, política pública seria o "Estado em ação" com vistas a atingir metas, objetivos e propósitos definidos (Heidemann, 2009; Rua, 1998; Saravia, 2006).

Existem algumas expressões correlatas que merecem considerações, tais como "políticas de Estado" e "políticas de governo". Consideram-se as "políticas de Estado" como mais inflexíveis ou perenes, o que se relaciona com serem previstas nas constituições ou em leis e serem realizadas por um corpo burocrático estável, permanecendo após eventuais mudanças no sistema político. Já as "políticas de governo" seriam políticas, progra- 
mas e projetos realizados por um partido ou governante sem a premissa de manutenção em longo prazo (Heidemann, 2009).

Outra expressão de interesse é "política social",que algumas vezes é associada com "política pública".As políticas sociais, na prática,englobam um enorme leque de políticas, tais como a educacional, a de saúde, a previdenciária, a de assistência social, a de cultura, a de esportes, dentre outras. A partir das definições supracitadas, todavia, também são políticas públicas outras ações governamentais que não são políticas sociais, tais como aquelas relacionadas às áreas fiscal, econômica, de defesa, de segurança pública e de relações exteriores.

Se o conceito de políticas públicas não é consensual, o mesmo ocorre com a definição de seu campo de estudo. Isso porque existe uma "confusão semântica" no uso dos termos "Análise de Políticas,",Análise de Políticas Públicas", "Avaliação de Políticas", “Ciência Política” e "Avaliação de Programas"1. Essa ambiguidade terminológica se relaciona com a própria origem desse campo. Apesar de se poder considerar que diversas ciências abordaram tangencialmente o campo das Políticas Públicas (em especial a Ciência Política), o estudo sistemático e direcionado nesse campo é considerado recente. Ele surge nos Estados Unidos na década de 1950 por demanda da própria administração pública, onde até então as pesquisas eram de pequena escala e pouco usadas nos processos de formulação e implementação (Dunn, 2008; Schneider, 2009).

Um marco colocado usualmente como fundador desse campo é a publicação em 1951 de "The Policy Science: Recent Developments in Scope and Method", por Harold Laswell e David Lerner. Nesse livro observa-se o esforço em fundar uma nova ciência aplicada que teria o objetivo de solucionar de forma racional os problemas relacionados à operacionalização da ação do Estado. A proposta desses autores, desse modo, previa um campo multidisciplinar destinado a acumular conhecimento para formulação e implementação de políticas (Dunn, 2008).

De acordo com Schneider (2009), os primeiros pesquisadores desse campo eram muitas vezes subordinados aos gestores públicos, que queriam respostas relativas à eficiência e eficácia dos processos por eles geridos. Dessa forma, surgem as avaliações dos processos envolvidos na implementação de políticas públicas (também chamadas de avaliações formativas), as avaliações de impacto (ou avaliações somativas, que visavam legitimar ou não uma política pública pela aferição de seus resultados objetivos) e os trabalhos de monitoramento. Nesse período inicial, o papel do analista era restrito, pois a definição de objetivos e métodos era usualmente feita pelos administradores. Cabia ao analista o papel de ava-

1 Observe-se que, em conformidade com as regras gramaticais, serão usadas letras iniciais maiúsculas para a acepção de "Políticas Públicas" como área de conhecimento, e minúsculas para o "Estado em ação". 
liador, de verificar se determinada política estava sendo implementada de forma eficaz (ou seja, se seus resultados atendiam aos objetivos do projeto), efetiva (se eram verificados os impactos supostos na fase de desenho de determinado programa) e eficiente (se os recursos materiais e humanos utilizados para produzir os resultados esperados eram razoáveis).

O campo de Análise de Políticas, por conseguinte, surge atrelado à concepção de avaliação de políticas e de programas, logo se restringindo aos aspectos técnicos relativos aos indicadores de programas e projetos governamentais.

Com o tempo, as duas expressões passaram a se ver muitas vezes combinadas, gerando uma ambiguidade terminológica. Observa-se, desse modo, que em determinadas ocasiões a "Avaliação de Políticas" (policy evaluation) é algumas vezes definida como o trabalho ou atividade de campo da "Análise de Políticas" (policy analysis) ou da Ciência de Políticas (policy science); em outras situações, todavia, são consideradas como sinônimos (Dye, 2002).

Andrews (2003), por outro lado, considera que esse movimento da década de 1950 de obter autonomia para a Ciência de Políticas (policy science) frente à Ciência Política (political science) pressupõe uma difícil neutralidade ou racionalidade da primeira, que, ao recortar a ação estatal como objeto de análise, o reifica em busca de uma legitimidade científica.

A partir do final da década de 1970, a ambiciosa ideia de um campo multidisciplinar capaz de verificar a eficácia dos programas aos poucos vai perdendo força, até mesmo porque seus subsídios estavam sendo pouco usados pelos gestores públicos. Os pesquisadores passaram a modificar seus objetos de estudo, enfocando menos os programas e mais o processo pelo qual ocorre a tomada de decisões. A introdução de métodos da Economia, da Análise de Sistemas, da Psicologia Matemática e das Ciências Sociais na Análise de Políticas Públicas forneceu instrumentos que permitiram aos avaliadores a superação do papel que lhes era reservado. Os pesquisadores nesse campo passaram a estudar questões acerca da relação custo-benefício das políticas, da adequação aos objetivos estabelecidos na legislação, dos processos de tomada de decisão, entre outros (Schneider, 2009).

Surgiu a partir dessa época uma ampla gama de modelos e referenciais teóricos e metodológicos. Como existem diversas formas de categorizá-los, faremos uma breve síntese considerando suas ênfases na racionalidade dos decisores e sua influência no desenho das políticas públicas brasileiras.

A Teoria da Escolha Racional (Racional Choice Model) é o principal referencial das abordagens racionalistas. Segundo esse paradigma, que possui forte influência da Economia, as políticas públicas devem preten- 
der atingir o máximo ganho social, cabendo ao analista identificar, entre as alternativas possíveis, a que garanta essa maximização. Os custos e os benefícios de todas as opções possíveis devem ser calculados com o objetivo de se perceber quais delas proporcionam a melhor equação financeira. Dessa forma, são preferidos métodos experimentais e semiexperimentais, pois são considerados mais confiáveis (Cohen \& Franco, 2004).

O emprego de indicadores para verificação sistemática da eficácia, eficiência e efetividade das políticas públicas é decorrente desse modelo, apresentando uma significativa difusão em alguns setores do poder público brasileiro, tais como o Ministério do Planejamento, Orçamento e Gestão, que os utiliza para concessão de orçamento para os demais ministérios. Objetiva-se, desse modo, quantificar os benefícios provenientes de determinada política para compará-los com os custos decorrentes de sua implementação. Parte-se do pressuposto de que os recursos são finitos e escassos, devendo o Estado utilizá-los com parcimônia (Cohen \& Franco, 2004).

Os Modelos Processuais partem do pressuposto de que não é possível se estudar a "substância" de uma política pública, sendo necessário parti-la em seus processos constituintes. Esses processos podem ser agregados em fases, tais como a de planejamento, implementação e avaliação. Desse modo, os defensores desse modelo consideram que a forma como uma política pública é formulada ou implementada pode ser diferente da concepção original da política, determinando seu sucesso ou fracasso (Dye, 2002).

É interessante ressaltar que o modelo mais em voga prevê fases como:a) identificação de problemas, em que as demandas para o Estado são manifestas; $b$ ) a constituição de uma agenda;c) a formulação de propostas; d) a legitimação, que muitas vezes se relaciona com a transformação de uma proposta em lei;e) a implementação de políticas; f) a avaliação de políticas (Dye, 2002).

O desenho do Estado Brasileiro também possui influências desse modelo, porquanto as atividades de gestão são concebidas como um ciclo e divididas entre órgãos de planejamento (no governo federal, exercidas majoritariamente pelo Ministério do Planejamento, Orçamento e Gestão), implementação (os ministérios e órgãos de execução) e avaliação (que inclui o Tribunal de Contas da União, o Instituto de Pesquisa Econômica Aplicada e unidades nos próprios órgãos executores).

É importante ressaltar também que essa divisão de uma política pública em fases permitiu pensar a privatização (ou publicização) de políticas incluídas na Constituição Federal de 1988. Isso porque no decorrer da década de 1990 houve um forte questionamento do papel do Estado na América Latina, em especial no atinente ao tamanho e à eficiência do setor público. Isso terminou por acelerar a adoção da Análise de Políticas Públicas nessa região, visto que esta foi nessa época colocada a serviço 
da reforma do Estado, por meio da implantação de sistemas de avaliação de eficiência dos programas governamentais. Assim, a Análise de Políticas foi usada para dar credibilidade às diversas iniciativas de retirar da esfera governamental a implementação de serviços públicos por meio da transferência dessas responsabilidades para organizações públicas não governamentais. Ao Estado caberiam as ações de planejamento, fomento, monitoramento e avaliação (Faria, 2005; Trevisan \& Van Belen, 2008).

A sociologia de Max Weber é outro importante marco teórico utilizado na Análise de Políticas Públicas, em especial os seus estudos acerca da organização e da divisão de poder no Estado. Trata-se de um referencial mais usado fora dos Estados Unidos, em países como o Canadá e o Brasil (Brooks, 2007).

As principais intersecções entre o pensamento weberiano e o campo das Políticas Públicas estão no conceito de Autoridade e na Teoria da Burocracia. Esse autor considera que a autoridade é uma forma de poder fundada nas posições das pessoas dentro de um determinado grupo ou sociedade. A autoridade não está ligada diretamente a um indivíduo, pois é estruturada pelas normas sociais. Desse modo, ela é mais duradoura do que o poder pessoal, que se constitui a partir das capacidades individuais, tais como força, inteligência, personalidade ou controle de recursos (Weber, 1964/2008).

Esse autor descreve três tipos de autoridade: a tradicional, que se baseia em uma percepção de que uma posição de autoridade é antiga e correta, logo dever ser considerada legítima; a carismática, que corresponde à atribuição de características mágicas ou extraordinárias a uma determinada pessoa, que se torna líder de determinado grupo ou sociedade; e a racional-legal, que se baseia em normas precisas e relativamente inflexíveis que geralmente são promulgadas pelos governos ou possuem sua origem neles (Weber, 2008).

A Teoria da Burocracia formulada por Max Weber se alicerça na concepção de autoridade racional-legal. Os sistemas burocráticos se constituem pela definição de normas e sistemas hierárquicos de forma explícita e rígida. Essas normas estabelecem uma minuciosa divisão do trabalho e de poderes, que normalmente são conferidos àqueles que supostamente possuem a mais qualificada competência técnica para exercê-los (Weber, 2008).

A influência da obra weberiana no desenho racional dos aparelhos burocráticos influenciou o desenho das máquinas administrativas da maior parte das democracias ocidentais. Mesmo o surgimento de novos modelos para a Administração Pública, como o "New Public Management", não resultou em um abandono do modelo burocrático. No Brasil, por exemplo, a recente reforma do aparelho estatal no governo de Fernando Henrique Cardoso propôs a implementação da Administração Gerencial no país sem abandonar esses ideais da burocracia clássica, tais como "a 
admissão segundo rígidos critérios de mérito, a existência de um sistema estruturado e universal de remuneração, as carreiras, a avaliação constante de desempenho, o treinamento sistemático" (Brasil, 1995).

Os modelos marxistas adquiriram maior visibilidade na década de 1970. Eles possuem o pressuposto de que as relações entre a economia, as classes sociais e o Estado determinam a consecução das políticas públicas. O Estado é visto como direcionado pelos interesses das classes dominantes, logo dotado apenas de uma autonomia relativa frente aos interesses do capital. Diversos referenciais que derivam da literatura marxista são utilizados para a análise de políticas públicas, incluindo a Teoria dos Aparelhos Ideológicos do Estado de Louis Althusser e a Teoria Crítica, cujos representantes contemporâneos são Junger Habermas e Claus Offe (Höffling, 2001; Rocha, 2005).

A hegemonia das abordagens racionalistas no campo das Políticas Públicas diminuiu na década de 1970. Com a ampliação do escopo desse campo, diversas abordagens, tais como o incrementalismo, a Teoria dos Jogos, o pluralismo e os modelos marxistas, passaram a refletir os conflitos teóricos existentes em outras disciplinas. O neoinstitucionalismo, todavia, e em especial a abordagem conhecida como o Garbage Can Model (o modelo da Cesta de Lixo), se destacou de todas essas correntes, pois ele refletiu a percepção de que as instituições que executam Políticas Públicas não são meras arenas para o combate entre os diferentes grupos de interesse que buscam no Estado satisfação para as suas demandas, ou que o gestor político possui plenas condições para fazer escolhas racionais, bastando para isso avaliar quais são as melhores opções (March \&Olsen, 2008).

Os autores neoinstitucionalistas consideram que o conceito de instituição submergiu na Ciência Política a partir da década de 1950. Seu resgate, no final da década de 1970 , se relaciona com a incapacidade da visão que até então dominava os estudos nessa área, que foi caracterizada como sendo:

(a) contextual, inclinada a ver a política como uma parte integral da sociedade e menos inclinada a diferenciar o Estado politicamente organizado do resto da sociedade; (b) reducionista, inclinada a ver os fenômenos políticos como as consequências agregadas dos comportamentos individuais e menos inclinada a atribuir os resultados da política às estruturas organizacionais e às regras de comportamento adequado; (c) utilitária, inclinada a ver a ação como o produto do interesse pessoal calculado e menos inclinada a ver os atores políticos como respondendo a obrigações e deveres; (d) funcionalista, inclinada a ver a história como um mecanismo eficiente no alcance de equilíbrios singularmente adequados e menos preocupada com as possibilidades de inadaptação e não singularidade no desenvolvimento histórico e (e) instrumentalista, inclinada a definir a tomada de decisões e a alocação de recursos 
como as preocupações centrais da vida política e menos atenta às maneiras pelas quais a vida política está organizada em torno do desenvolvimento de significados, por meio de símbolos, rituais e cerimônias. (March \& Olsen, 2008, p. 122)

Se o neoinstitucionalismo se diferencia das teorias racionalistas por sobrelevar os aspectos irracionais envolvidos no processo de tomada de decisão por parte dos gestores, ele também se contrapõe ao pluralismo e ao marxismo, pois essas abordagens unem-se na ênfase analítica no papel da sociedade nos processos de tomada de decisão, variando apenas no tamanho da influência dos grupos sociais. Em síntese, pode-se dizer que o pluralismo tende a considerar o Estado como um fórum no qual os grupos pactuam acordos para produção de resultados por eles demandados e os referenciais teóricos inspirados no marxismo percebem o aparelho estatal como inexoravelmente subserviente aos interesses do capital (Rocha, 2005).

A retomada do foco institucional se relaciona com a percepção das limitações das abordagens em voga: a inserção de um tema na agenda política, por exemplo, não necessariamente gera políticas públicas que refletem o processo político de tomada de decisão. Os políticos e os eleitores não tomam necessariamente decisões racionais, que lhes tragam melhores resultados, quantificáveis por meio de uma relação custo-benefício. Ademais, não é incomum que dirigentes criem consensos em relação a determinadas agendas, anunciem planos de reformas e em seguida abram mão delas por não conseguir implementá-las. As instituições, dessa forma, possuem um papel atuante na implementação de políticas públicas, não constituindo apenas meros espelhos da sociedade ou de suas classes dominantes. Legislações e políticas públicas que encontraram uma instituição capaz de implementá-las tornaram-se efetivas, e as que não encontraram permanecem como agendas ou planos (March \& Olsen, 2008).

March (1994) considera que, assim como na História e na Ciência, os tomadores de decisão no âmbito das organizações tentam estabelecer relações causais para explicar eventos ambíguos. Os responsáveis pelas decisões fazem inferências a partir de suas percepções da realidade e de suas histórias pessoais. Tais inferências muitas vezes se baseiam em crenças arraigadas e antropocêntricas, que resistem à experiência empírica. Ademais, como muitos decisores alçaram suas posições em decorrência de sucessos pretéritos, esses possuem uma maior tendência a incorrer nos desvios supracitados, por terem tido sucesso no passado.

Desse modo, percebe-se que outra questão relevante para o neoinstitucionalismo é a ambiguidade dos próprios decisores. March (1994) considera que as preferências de uma pessoa não são necessariamente consistentes, estáveis e exógenas ao processo de escolha, pois elas podem mudá-la de acordo com as contingências. Uma avaliação racional 
pode ser substituída por outra, em conformidade com o cenário atual. Muitas vezes, entretanto, isso acontece em conformidade com o que o ator imagina conscientemente ou não que as pessoas à sua volta julgariam adequado, e não de acordo com ponderações lógicas.

Desse modo, apesar de as organizações possuírem diversas estruturas e procedimentos que deveriam levar a ações coordenadas, elas exibem diversos sintomas de incoerência. $O$ fato de os problemas, as soluções e os decisores mudarem constantemente, bem como as limitações de atenção e memória por parte dos decisores, fazem com que as decisões sejam desconectadas das ações, as ações de ontem sejam desconectadas das de hoje, as justificativas sejam desconectadas das decisões e os problemas desconectados de suas soluções. Soluções racionais, desse modo, são constantemente abandonadas e jogadas na "cesta de lixo", pois o que era solução ontem já não é mais hoje (March \& Olsen, 2008).

Outro ponto a ser considerado é a necessidade de construção de significados. March (1994) observa que mais do que decisões racionais, as pessoas precisam elaborar significados para os acontecimentos que as circundam. Esse autor faz diversas analogias entre mitos, símbolos e rituais presentes em diversas sociedades e os papéis, símbolos de status e comportamentos de uma organização. Os processos de tomada de decisão, desse modo, buscam dar sentido aos procedimentos internos, não se circunscrevendo aos seus objetos específicos.

Assim, a tomada de decisão e as atividades que a circundam possuem uma considerável importância simbólica. Durante a tomada de decisão, os decisores desenvolvem significados não apenas sobre as decisões, mas também sobre a verdade, sobre o que está acontecendo no mundo e porque está acontecendo. Eles, desse modo, por meio de suas decisões, definem o que é moralmente importante e o que é um comportamento apropriado. Eles elaboraram uma linguagem de compreensão e descrevem como as ações são apropriadamente explicadas e justificadas. Assim, eles também alocam e definem o valor individual, definindo os sentidos que permitem compreender quem se destaca no âmbito da organização (March, 1994).

Sob essa perspectiva, as organizações parecem um caos quando vistas pelas teorias convencionais. Os grandes triunfos da burocratização weberiana, tais como a departamentalização, descentralização e hierarquização, são mais úteis para conciliar a incoerência interna do que para coordenar as ações organizacionais (March, 1994).

\section{A subjetividade, o poder e a análise de políticas públicas}

Se o neoinstitucionalismo é uma das respostas mais contundentes às limitações das teorias racionalistas no campo das Políticas Públicas, 
existem também críticas a essas abordagens na Psicologia. É interessante, nesse contexto, sobrelevar os subsídios da Psicossociologia francesa, visto que alguns de seus autores trataram pontualmente das limitações dos referenciais supramencionados, ainda que não com o enfoque em Políticas Públicas. Um dos seus maiores expoentes, Eugene Enriquez, é um crítico de diversas teorias racionalistas e também das teorias de tomada de decisão. Em seu entender, muitas dessas teorias, por enfatizarem os aspectos econômicos ou comportamentais de seus objetos de estudo, simplificam como "processos de tomada de decisão" questões que se relacionam com os mecanismos de obtenção e manutenção do poder. Esses mecanismos, além disso, não são objetivos, pois se relacionam também com nossas necessidades e angústias.

O poder, em suas acepções políticas, não existe objetivamente, pois se trata de uma relação entre pessoas, na qual algumas assumem posições de dominação e outras de submissão. Mesmo que as relações e as posições mudem, e mesmo que os mecanismos que sustentam essas relações não sejam evidentes em uma análise superficial, sempre existe uma assimetria entre as pessoas envolvidas nessas relações. Ressalta-se, desse modo, a natureza ambígua do poder, pois, ao mesmo tempo em que ele se manifesta pela persuasão, pela liderança e pela sedução, ele possui um forte aspecto coercitivo (Barus-Michel, 2004; Barus-Michel \& Enriquez, 2009).

As primeiras experiências de poder surgem na relação entre pais e filhos. A longa imaturidade da criança a submete ao poder dos pais e familiares. É a figura do pai que impõe os limites, definindo o que é e o que não é permitido: os contatos iniciais com a lei e com a interdição de seus desejos. Se a figura paterna se mostrar adequada, as crianças tendem a internalizar essa interdição, se identificando com as figuras parentais e formando um superego (Barus-Michel \& Enriquez, 2009; Enriquez, 2007).

Observa-se que a função paterna é mais abrangente que a do pai biológico, pois se relaciona com os aspectos estruturantes da psique humana, incluindo também a paternidade legal (o registro do pai que consta nos documentos oficiais), a paternidade social (o provedor, o educador, o responsável legal) e a paternidade simbólica (a lei introjetada, o interdito) (Sudbrack, 2003).

Se o filho concorda em obedecer aos pais, mas não internaliza essas interdições - o que ocorre em especial quando elas são impostas de modo violento -, considera-se que o filho foi castrado simbolicamente. A ausência de identificação leva a criança a querer fantasiosamente tomar o lugar da figura paterna. A permanência dessas fantasias limita a relação dessas pessoas com a realidade. Isso também acontece quando não ocorrem limitações ou interditos, por fraqueza ou ausência da figura paterna, pois a falta de algo a introjetar não permite a estruturação de um superego sólido (Enriquez, 2007). 
O poder, em consequência disso, possui uma dimensão imaginária, pois aqueles que se submetem a ele possuem a crença de que os que $o$ possuem são capazes de garantir a sua estabilidade, o seu bem-estar, e, dessa maneira, projetarão suas vivências familiares em seus dominadores. Por conseguinte, o poder se estrutura pela falta. As pessoas buscam projetar representações, afetos e expectativas em alguém. Quando encontram alguma pessoa que se mostra disposta a compensar essas faltas, que tem ou que demonstra ter algo que os demais precisam, estabelecese uma relação de poder (Barus-Michel \& Enriquez, 2009).

Ademais, a ambivalência das relações familiares também pode ser projetada nas relações de poder, manifestando-se por meio da revolta e da rebelião. O poder é, desse modo, uma relação instável e ambivalente, visto que ela precisa ser continuadamente reconsolidada, pois é baseada no imaginário (Barus-Michel, 2004; Enriquez, 2007).

Evidentemente os jogos de poder da sociedade são mais complexos do que os dos primeiros anos de vida de uma pessoa. Boa parte das pessoas possui simultaneamente papéis de dominadores e de dominados, quer seja em um mesmo contexto ou em contextos diferentes, tecendo organogramas e redes de poder. A História se caracteriza pelas relações de violência, o que é observável pela escravidão de povos inteiros derrotados em guerras, pelas pilhagens, pelo sequestro de mulheres e pelos genocídios que atravessaram os séculos (Enriquez, 2007).

A posse de meios de sanção é, desse modo, a fonte de poder mais utilizada. Todavia, sua influência diminuiu nos últimos séculos frente ao crescimento de formas consideradas mais legítimas de poder, abrangidas na sociologia de Max Weber pelo conceito de autoridade. $O$ uso exclusivo de sanções passou algumas vezes a retirar a legitimidade da autoridade que as aplica, o que levou à busca de outras formas de dominação. Isso, todavia, não fez com que essa fonte desaparecesse, sendo utilizada por muitos chefes nos dias atuais (Barus-Michel, 2004; Enriquez, 2007).

Existem na literatura psicológica, antropológica e sociológica diversos inventários de fontes de poder.Com base na relação de Enriquez (2007) elencamos algumas dessas fontes, focando em especial as que se mostraram mais apropriadas ao objeto deste artigo. Como todas essas fontes são falíveis, o comum é que elas sejam conjugadas, de modo que seus usos individuais são raros:

\footnotetext{
A identificação é uma das primeiras formas de poder que conhecemos em nossas vidas. Como já foi dito, se as crianças conseguem perceber o sentido das limitações que lhes são impostas pela figura paterna, elas passam a introjetar essas limitações, criando para si um ideal de ego que passa a nortear suas ações. Esse processo se mantém durante a adolescência e a vida adulta, pois podemos constantemente nos identificar com professores nas escolas, com chefes ou colegas nas organizações ou com membros de outros grupos sociais (Enriquez, 2007).
} 
O amor-fusão é um conceito derivado do conceito de autoridade carismática de Max Weber (2008) e também dos conceitos de liderança de Sigmund Freud (1930/2010). Ocorre quando uma pessoa estabelece uma forte relação projetiva com outra que assume um papel de liderança. Essa projeção faz com que seus seguidores considerem que ela possui poderes mágicos ou transcendentais. Em tal caso, o poder é apreendido como sagrado, o que faz com que seus seguidores não admitam a reflexão ou a crítica no que concerne à sua natureza. Sua legitimidade no âmbito político é proveniente de supostos milagres, das vitórias ou da prosperidade dos que estão sob seu domínio (Barus-Michel, 2004; Enriquez, 2007).

A forte catexia que liga dominadores e dominados faz com que as tentativas de autonomia originem mecanismos de defesa, em especial a repressão. Os dominadores impõem atos, palavras e ritos específicos que ressaltam os seus aspectos sobre-humanos. Seus seguidores aceitam essas restrições, pois elas permitem diversos ganhos secundários, tais como as fantasias de proteção e de partilha de algumas das capacidades do líder (Enriquez, 2007).

A legitimidade corresponde à aceitação do poder pela tradição, correspondendo à autoridade tradicional weberiana. A legitimidade aumenta a perenidade de uma relação de poder, pois suas outras fontes, tais como a identificação, o amor-fusão e o uso de meios de sanção, podem ser mais facilmente substituídas. Ela, entretanto, é fruto de contingências históricas, culturais ou meramente situacionais, refletindo usualmente a dominação de um grupo social pelo outro (Enriquez, 2007; Weber, 2008).

A competência técnica se relaciona com as concepções de Weber acerca da consolidação da burocracia como forma de distribuição de poder nas organizações formais. A autoridade, nesse caso, se relaciona com o domínio estrito dos conhecimentos e habilidades relacionados ao papel específico de cada pessoa dentro de organizações, instituições ou no governo. Os cargos, funções e profissões não possuem uma faceta mágica ou sobre-humana, devendo ser ocupados por pessoas que comprovem qualificação para exercê-los - o que torna importante a comprovação desses méritos por meio de diplomas, provas e experiências profissionais pregressas (Enriquez, 2007; Weber, 2008).

A competência humana se relaciona com as capacidades individuais das pessoas. Esse conceito inclui aspectos como inteligência, motivação, concentração, agressividade, dentre outros. O desenvolvimento das técnicas de avaliação psicológica no decorrer do século $\mathrm{XX}$, bem como o surgimento de abordagens na área de gestão que valorizam traços de personalidade (tais como a Inteligência Emocional e a Abordagem por competências), refletem a percepção de que desenhar cargos e funções de modo adequado ou científico era insuficiente para 
manter o crescimento da eficiência dos processos administrativos (Enriquez, 1997a, 2007).

Por outro lado, a posição de uma pessoa em uma estrutura organizacional e a posse de competência técnica e humana não são suficientes para garantir-lhe poder, pois, como esse possui uma natureza relacional, ele depende do contexto no qual os profissionais estão inseridos. O fluxo de comunicações entre as pessoas, os funcionários que efetivamente possuem legitimidade para resolver determinados assuntos, a incapacidade dos gerentes de ter conhecimento de todos os processos para a tomada de decisões, dentre inúmeros outros fatores, fazem com que a estrutura de relações e a posse dos meios de controle sejam determinantes na partilha do poder no interior das organizações. Tais fatores foram abordados neste trabalho na apresentação do Garbage Can Model, sendo desnecessárias novas considerações (Enriquez, 2007).

Apesar de ser possível encontrar em qualquer instituição todas as formas supramencionadas de poder, é comum que algumas dessas se destaquem. Enriquez propõe uma tipologia de estruturas das organizações, que relaciona estruturas organizacionais baseadas parcialmente nos tipos de autoridade weberianos com os mecanismos de defesa e estruturas de personalidade da psicanálise (Enriquez, 1997a).

A estrutura carismática é constituída ao redor de líderes que recebem projeções relacionadas às suas supostas capacidades. Ela pressupõe, dessa forma, mecanismos de sedução entre os dirigentes e subordinados, e gera como consequências competições, suspeitas, divisões e dissimulações entre os funcionários, muitas vezes ocultas pela emulação do chefe. Instituições e organizações com estruturas carismáticas possuem em maior quantidade pessoas com personalidades paranoicas, pois partem do pressuposto de que deve existir um inimigo externo que deve ser destruído. Também se encontram nelas personalidades megalomaníacas, pois essas usualmente prometem coisas impossíveis, falando mais ao imaginário das pessoas ou populações do que para o ego (Enriquez, 1997a).

O ideal da estrutura burocrática é a criação de um mundo onde os humanos e os subordinados sejam atores e objetos de um cerimonial preciso. Ele inclui a normatização precisa e impessoal do funcionamento de uma organização, com divisões bem definidas de trabalho e atribuições. Essa estrutura se coaduna com personalidades obsessivas, pois a burocratização permite a redução das tensões (Enriquez, 1997a).

A estrutura tecnocrática tem como paradigma a racionalidade ilimitada, sendo outra faceta da ascensão do paradigma burocrático. $O$ poder, no contexto dessa estrutura, é conferido a experts, capazes não somente de lidar com os problemas à medida que eles surgem, mas também de prevê-los por meio de cenários e simulações. O tecnocrata, nesse contexto, desconsidera os aspectos subjetivos envolvidos na implementa- 
ção de suas políticas e decisões, reduzindo as discussões políticas e éticas a seus aspectos racionais e objetivos. Encontra-se nessas estruturas um maior número de personalidades perversas (Enriquez, 1997a).

Enriquez (1997b) contrapõe às estruturas tecnocrática e burocrática a estrutura estratégica. Há nessa última a percepção de que a racionalidade é limitada, e que para isso é mais importante o direcionamento estratégico de ações de curto prazo do que o planejamento de ações de longo prazo. Os tecnocratas e burocratas clássicos, aos poucos, têm perdido o poder nas últimas décadas pela imprevisibilidade dos cenários originados pela globalização da economia e pelo consequente aumento da incidência de acontecimentos - em especial crises - que não foram previstos por grande parte dos técnicos governamentais.

A estrutura estratégica, dessa forma, se relaciona com a substituição do planejamento ditado por tecnocratas e executado por burocratas por estratégias adotadas por todos os níveis hierárquicos no mundo governamental e corporativo. Isso porque todos precisam se envolver e se adaptar às novas demandas do sistema capitalista. Diversas necessidades originadas pela globalização, tais como resultados, manutenção do compromisso dos funcionários e cumprimento de prazos, têm levado os gestores a adotar táticas cada vez menos usuais de treinamento, tais como cursos de sobrevivência em selvas e outros eventos esportivos. O líder, nesse contexto, é alguém que seduz as pessoas para o trabalho, demonstrando suas competências de comunicação cotidianamente (Enriquez, 1997b).

Por derradeiro, a estrutura cooperativa seria aquela na qual o poder seria partilhado por todos os profissionais envolvidos, que passam a assumir compromissos não somente entre suas responsabilidades, mas também entre seus desejos. Mesmo sendo a mais próxima de uma estrutura saudável, existem nela questões de poder. As pessoas buscam conversar no sentido de estabelecer compromissos entre os seus desejos e os dos outros. Isso origina um sentimento de estranheza em quem dela toma parte, pois falar de questões de poder, perceber seus desejos e levar em consideração os do outro depende de uma abertura para a percepção das faltas e das fantasias de cada indivíduo, bem como de um grau de tolerância para as ansiedades e ambiguidades originadas pela convivência institucional (Enriquez, 1997a).

\section{Intersecções teóricas}

A enumeração das fontes e estruturas de poder em conformidade com o referencial psicossociológico em justaposição a alguns dos modelos clássicos da Análise de Políticas Públicas mostra que existem diversas questões relativas à implementação das ações governamentais que po- 
deriam ser melhor compreendidas pela percepção dos aspectos subjetivos dos responsáveis pela faceta operacional do Estado. Constitui, todavia, uma limitação deste trabalho não poder cobrir todas as possibilidades de intersecção entre esses campos, destacando-se apenas as mais evidentes:

Inicialmente, observa-se que, assim como o neoinstitucionalismo se propõe a compreender os motivos de determinadas políticas não apresentarem os resultados esperados apesar de seu planejamento atender a todos os imperativos racionais, os conceitos psicossociológicos de estruturas institucionais e de mecanismos de legitimação do poder oferecem um arcabouço teórico para o entendimento do insucesso de diversas ações governamentais, em especial aquelas nas quais a subjetividade dos atores apresenta um papel ímpar.

Um bom exemplo seria o das políticas de segurança pública. As polícias brasileiras possuem sérios conflitos entre si. Somos o único país do mundo que possui duas polícias estaduais de meio ciclo (uma militar responsável pelo policiamento ostensivo e outra civil voltada para a investigação policial). Esse desenho é duramente criticado por alguns especialistas pela sua irracionalidade, pois ele implica um expressivo dispêndio de recursos. Isso porque, dentre outros fatores, cada área territorial precisa ter repartições das duas polícias; os policiais militares, ao realizarem uma prisão, precisam dirigir-se a um delegado de polícia civil, que ratifica a prisão (mesmo que os policiais tenham que viajar centenas de quilômetros para isso), e as duas polícias possuem unidades para complementar o papel da outra (os setores de investigação reservada das polícias militares e os grupos de operações especiais das civis). As diversas tentativas de modificar essa situação (tais como o Sistema Único de Segurança Pública e a Conferência Nacional de Segurança Pública, ações cujos arcabouços teóricos possuem algumas similaridades com a estrutura cooperativa) foram ineficazes diante da ação dos atores políticos dessas duas instituições, que utilizam diversos argumentos para legitimar a manutenção deste status quo, grande parte deles relacionados à competência técnica.

Desse modo, a conflituosa história das duas instituições, os mitos que legitimam suas existências, bem como o processo de constituição e transmissão de conhecimentos de suas burocracias e os temores, tornam possível estabelecer a hipótese de que alguns dos motivos que impedem uma evolução da arquitetura organizacional das políticas de segurança pública se relacionam com o uso pelos atores envolvidos de mecanismos de poder tais como a identificação, o amor-fusão e a posse de meios de sanção.

Outro elemento interseccional é a descontinuidade das ações nas organizações. O neoinstitucionalismo (e em especial o Garbage Can Model) se contrapõe às abordagens racionalistas pela afirmação da im- 
previsibilidade dos resultados das políticas públicas, devido ao fluxo caótico de soluções, problemas e decisores. A Psicossociologia por um lado corrobora essa visão, pois constata as dificuldades das instituições em se manter coesas, constituindo o poder uma forma tênue de garantir a incolumidade institucional. Justamente por manter essa ordem, a Psicossociologia se distingue dos autores neoinstitucionalistas ao apresentar elementos subjetivos que asseguram a frágil integração do ser humano em organizações, que são oriundos dos alicerces psíquicos que garantem a inserção do homem na cultura e na civilização. Além disso, a descrição das estruturas burocráticas, tecnocráticas e estratégicas permite compreender porque - e a que custo - algumas instituições possuem mais eficácia em suas ações de planejamento do que outras.

Por derradeiro, deve-se sobrelevar que a própria constituição do campo das Políticas Públicas se relacionou com o surgimento da estrutura tecnocrática. A percepção existente nos primórdios da policy analisys de que as Políticas Públicas poderiam ser analisadas de modo científico e distinto das relações de poder (e, por conseguinte, da subjetividade dos atores envolvidos) pode encobrir a fantasia perversa de controlar a sociedade pelo planejamento absoluto.Tal intersecção, pelas questões éticas que sugere, poderia ser objeto de futuros estudos.

\section{Conclusões}

A existência do campo de Políticas Públicas, que não tem sido usualmente observada nos esforços de pesquisa até então realizados pela Psicologia, ao mesmo tempo em que abre novas oportunidades de construção de saberes multi, inter e transdisciplinares, termina por exigir do psicólogo atenção para a existência de referenciais, conhecimentos e práticas acumulados nessa área que são usados no desenho das ações governamentais em nosso e em outros países.

Por outro lado, é importante sobrelevar que a Psicologia possui relevantes subsídios para uma melhor compreensão da limitação das abordagens racionalistas, que são usualmente utilizadas no desenho das políticas públicas em âmbito federal. Sem desconsiderar que a introdução dessas abordagens teve o mérito de atenuar o desperdício de recursos públicos com ações clientelistas ou patrimonialistas, seria um inegável avanço se o planejamento das políticas públicas também passasse a considerar os aspectos subjetivos que envolvem tanto os atores públicos quanto a sociedade.

Urge ressaltar, por fim, que a inserção dos psicólogos no campo das Políticas Públicas se dá com muita frequência por meio de suas contratações pelo Estado. Desse modo, a atuação dos psicólogos no serviço público possui uma inexorável implicação com relações de poder,e, 
por conseguinte, com aspectos éticos e deontológicos da categoria. Isso faz com que sejam importantes novos trabalhos que permitam uma compreensão mais abrangente das relações entre esses dois campos do saber.

\section{Subjectivity, policy analysis and power: theoretical models and intersections}

Abstract:This article aims to present some thoughts and criticisms about the theories of public policy analysis, focusing on the role of subjectivity in the process of decisionmaking and power struggles. It presents the main theoretical models of this field that are used in Brazil and subsidies to Psychosociology understanding of issues of subjectivity and power, as well as some of their intersections. In conclusion, the article presents some points to be considered in the approximation of the knowledge areas.

Keywords: Public policy. Public administration. Power. Subjectivity.

\section{Subjectivité, analyse des politiques et pouvoir: matrices et intersections théoriques}

Résumé: Cet article vise à présenter quelques réflexions et des critiques sur les théories de l'analyse des politiques publiques, en se concentrant sur le rôle de la subjectivité dans le processus de prise de décision et de luttes de pouvoir. L'article présente les principaux modèles théoriques de ce domaine qui sont utilisés au Brésil et en subventions à la compréhension de Psychosociologie des questions de subjectivité et de puissance, ainsi que certains de leurs intersections. En conclusion, nous présentons quelques points à considérer dans le rapprochement de ces deux disciplines.

Mots-clés: Politique publique. Administration publique. Pouvoir. Subjectivité. 
Análisis de políticas públicas, subjetividad y poder: matrizes y intersecciones teóricas

Resumen: Este artículo tiene como objetivo presentar algunas reflexiones y críticas sobre las teorías de análisis de políticas públicas, centrándose en el papel de la subjetividad en los procesos de tomada de decisiones y en las luchas de poder. Se muestran los principales modelos teóricos de este campo y los conocimientos de la Psicosociología para la comprensión de las cuestiones de la subjetividad y el poder. En conclusión, se presentan algunos puntos a considerar para que esas dos disciplinas aproxímense.

Palabras clave: Políticas públicas. Administración pública. Poder. Subjetividad.

\section{Referências}

Andrews, C.W. (2003). Reificação e legitimidade: Habermas como metateoria das Policy Sciences. Tese de Doutorado, Faculdade de Filosofia, Letras e Ciências Humanas, Universidade de São Paulo, São Paulo.

Barus-Michel, J. (2004). O sujeito social (E. D. Galery \& V. M. Machado, trads.). Belo Horizonte:Ed.PUC-Minas.

Barus-Michel, J., \& Enriquez, E. (2009). Pouvoir. In J. Barus-Michel, E. Enriquez \& A. Levy (Eds.), Vocabulaire de psychosociologie:Positions et références (pp.212221). Ramonville Saint-Agne: Érès.

Bobbio, N., Matteucci, N., \& Pasquino, G. (1998). Dicionário de política (C. C.Varriale, trad., 11 a ed.). Brasília, DF: Ed. da Universidade de Brasília.

Brasil. Presidência da República. (1995). Plano Diretor da Reforma do Aparelho do Estado. Brasília, DF: Autor.

Brooks, S. (2007). The policy analysis profession in Canada. In L. Dobuzinskis, M. Howlett \& D. Laycock (Eds.), Policy analysis in Canada: The state of the art. Toronto: University of Toronto Press.

Cohen, E., \& Franco, R. (2004). Avaliação de projetos sociais (6a ed.) Petrópolis, RJ: Vozes.

Cruz, L. R., \& Guareschi, N. (2009). A constituição da assistência social como política pública: interrogações à psicologia. In L. R. Cruz \& N. Guareschi, Políticas 
públicas e assistência social: diálogos com as práticas psicológicas (pp. 1339). Petrópolis, RJ:Vozes.

Dunn, W. N. (2008). Public policy analysis: An introduction. Upper Saddle River: Pearson Prentice Hall.

Dye, T. R. (2002). Understanding public policy (10th ed.). Upper Saddle River: Pearson Prentice Hall.

Enriquez, E.(1997a). Les jeux du pouvoir et du desir dans l'entreprise. Paris:Desclée de Brouwer.

Enriquez, E.(1997b). O indivíduo preso na armadilha da estrutura estratégica. $R A E$ - Revista de Administração de Empresas, 37(1), 18-29.

Enriquez, E.(2003).L'Organisation en analyse (4a ed.). Paris: Presses Universitaires de France.

Enriquez E. (2005). Psicanálise e ciências sociais. Ágora, 8(2), 153-174.

Enriquez, E. (2007). As figuras do poder (N. de Melo, trad.). São Paulo:Via Lettera.

Faria, C. A.P. (2005). A política de avaliação das políticas públicas. Revista Brasileira de Ciências Sociais, 20(59), 97-109.

Ferreira, A. B. H. (1986). Novo dicionário Aurélio da Língua Portuguesa (2a ed. rev. e ampl.). Rio de Janeiro: Nova Fronteira.

Ferreira, V.R. de M. (2008). Psicologia econômica:estudo do comportamento econômico e da tomada de decisão. Origens, modelos, propostas. Rio de Janeiro:Elsevier.

Freud, S. (2010). O mal-estar na cultura (R. Zwick, trad.). Porto Alegre: L\&PM. (Trabalho original publicado em 1930)

Gonçalves, M. G. M. (2010). Psicologia, subjetividade e políticas públicas. São Paulo:Cortez.

Heidemann, F.G.(2009).Do sonho do progresso às políticas de desenvolvimento. In F. G. Heidemann \& J. F. Salm, Políticas públicas e desenvolvimento: bases epistemológicas e modelos de análise (pp. 23-40). Brasília, DF:Ed. da Universidade de Brasília.

Höffling, E. M. (2001).Estado e políticas (públicas) sociais. Cadernos Cedes, 21(55), 30-41. 
March, J. G. (1994). A primer on Decision Marking: How decisions happen. Nova York: Free Press.

March, J.G., \& Olsen, J.P. (2008). Neoinstitucionalismo: fatores organizacionais da vida política. Revista de Sociologia e Política, 16(31), 121-142.

Morin, E. (2002). Educação e complexidade: os sete saberes e outros ensaios. São Paulo: Cortez.

Nay, O. (2007). História das ideias políticas (J.A. Clasen, trad.). Petrópolis, RJ:Vozes.

Rocha, C.V. (2005). Neoinstitucionalismo como modelo de análise para as políticas públicas - Algumas observações. Civitas: Revista de Ciências Sociais, 5(1), $11-28$.

Rua, M. G. (1998). As políticas públicas e a juventude dos anos 90. In M. G. Rua, Jovens acontecendo na trilha das políticas públicas (Vol.2, pp.731-752 ).Brasília, DF: CNPq.

Saravia, E. (2006). Política pública: dos clássicos às modernas abordagens. Orientação para leitura. In E. Saravia \& E. Ferrarezi (Orgs.), Políticas públicas: coletânea (Vol.2). Brasília, DF: ENAP.

Scarparo, M.L. D.-E., \& Poli, M. C. (2009). Psicanálise e assistência social. In L. R. Cruz \& N. Guareschi, Políticas Públicas e Assistência Social: diálogos com as práticas psicológicas (pp. 124-150). Petrópolis, RJ:Vozes.

Schneider, A. L. (2009). Pesquisa avaliativa e melhoria da decisão política: evolução histórica e guia prático. In F.G. Heidemann \& J. F.Salm, Políticas Públicas e Desenvolvimento: bases epistemológicas e modelos de análise (pp.311-327). Brasília: Ed. da Universidade de Brasília.

Sudbrack, M. F. O. (2003). Da obrigação à demanda, do risco à proteção e da dependência à liberdade: abordagem da drogadição de adolescentes. In M. F. O. Sudbrack, N. I. G. Conceição, E. M. F. Seidl \& M. T. Silva, Adolescentes e drogas no contexto da Justiça (pp.47-79). Brasília, DF: Plano.

Trevisan, A.P., \& Van Bellen, H.M. (2008). Avaliação de políticas públicas: uma revisão teórica de um campo em construção. Revista de Administração Pública, 42(3), 529-550.

Weber, M. (2008). Ensaios de Sociologia (W. Dutra, trad., 5a ed.). Rio de Janeiro: LTC.

Worthen, B. R., Sanders, J. R., \& Fitzpatrick, J. L. (2004). Avaliação de programas: concepções e práticas (D. A. Azevedo, trad.). São Paulo: Gente. 
Gustavo Camilo Baptista, psicólogo e mestre em Educação pela Universidade de São Paulo e doutorando em Psicologia Clínica e Cultura pela Universidade de Brasília. É membro da carreira de especialista em Políticas Públicas e Gestão Governamental do Ministério do Planejamento, Orçamento e Gestão. Endereço para correspondência: Caixa Postal 4314, Brasília, DF, Brasil. CEP: 70904-970. Endereço eletrônico: gustavocamilobaptista@yahoo.com.br

Recebido: 01/02/2]011

Aceito: $24 / 08 / 2011$ 